\title{
SCLERAL PERFORATIONS DURING PERIBULBAR ANAESTHESIA
}

\author{
A. M. MOUNT and H. C. SEWARD \\ Croydon
}

\begin{abstract}
SUMMARY
Scleral perforation is a recognised but uncommon complication of retrobulbar and peribulbar anaesthesia; most of the reported cases have required further intervention. We report 5 cases from our department that occurred between October 1991 and June 1992. Surgery was performed in all 5 cases without complications. Vitreous haemorrhage was noted on the first post-operative day in all patients; none of the patients required further intervention. Four of 5 patients achieved a final visual acuity of $6 / 9$ and the fifth case was an amblyopic eye with a final acuity of $6 / 18$.
\end{abstract}

Peribulbar anaesthesia was introduced in 1986 by Davis and Mandel $^{1}$ as an attempt to reduce the complications associated with retrobulbar anaesthesia, namely brain stem anaesthesia, retrobulbar haemorrhage and scleral perforation. We present a series of 5 patients with scleral perforations who attended the Croydon Eye Unit between October 1991 and June 1992. We document their progress and final visual acuity following the initial injury.

\section{METHODS}

We retrospectively reviewed the case notes of 5 patients with scleral perforation. All 5 had had a peribulbar anaesthetic administered with a 25 gauge retrobulbar needle. The first injection was through the lower lid at the junction of the middle and lateral thirds, the second just under the trochlea. Nothing unusual was noticed during administration of the block and all operations proceeded uneventfully.

\section{RESULTS}

All 5 patients were women, with a mean age of 74 years (range 63-82 years). Four of the 5 underwent cataract extraction, and 1 had repositioning of a dislocated intraocular lens 4 months after cataract surgery. Axial length measurements ranged from 22.14 to $25.98 \mathrm{~mm}$ (mean $23.9 \mathrm{~mm}$ ) (Table I).

Correspondence to: Miss A. Mount, Croydon Eye Unit, 33 Mayday Road, Croydon, Surrey CR7 7XN, UK.
The anaesthetic was given by a Consultant Anaesthetist in 3 cases and by SHO ophthalmologists in 2 cases. Between October 1991 and June 1992, 666 local anaesthetics were performed in our unit; this gives a perforation rate of $0.75 \%$.

On the first post-operative day, visual acuity ranged from hand movements to $6 / 6$ and vitreous haemorrhage was noted in all cases. The vitreous haemorrhage prevented fundal examination in 1 case and this patient underwent a B-scan. All 5 eyes were found to have a flat retina. On subsequent examination no patient was found to have a retinal tear or detachment.

All 5 were seen to have linear white scars in the periphery; 3 were superonasal (Fig. 1) and 2 were inferotemporal (Fig. 2). One patient was referred to a vitreoretinal surgeon, who felt that no further intervention was required. No further treatment was undertaken in any of the 5 cases and follow-up has revealed no change in retinal appearance. The duration of follow-up ranged from 10 to 17 months with a mean of 12.6 months. Best corrected visual acuity was $6 / 9$ or better in all cases except case 2, which was an amblyopic eye that was correctable to $6 / 18$.

\section{DISCUSSION}

Ocular perforation and penetration during the administration of local anaesthesia has frequently been reported Ramsey et $_{\text {al. }}{ }^{2}$ described 3 cases during retrobulbar anaesthesia for retinal detachment surgery and Rinkoff et $a l^{3}{ }^{3}$ reported 12 cases in 1991, all resulting from use of the

Table I. Details of cases

\begin{tabular}{lccccc}
\hline & Case 1 & Case 2 & Case 3 & Case 4 & Case 5 \\
\hline Age (yr) & 71 & 79 & 63 & 82 & 74 \\
Axial length (mm) & 22.14 & 25.98 & 24.28 & 24.11 & 23.01 \\
Injector & Anaes. & SHO & SHO & Anaes. & Anaes. \\
VA day 1 & $3 / 60$ & CF & CF & HM & $6 / 6$ \\
Site & Nasal & Nasal & Temporal & Nasal & Temporal \\
Final VA & $6 / 9$ & $6 / 18^{\mathrm{a}}$ & $6 / 9$ & $6 / 9$ & $6 / 6$ \\
Follow-up (months) & 17 & 13 & 12 & 10 & 11 \\
\hline
\end{tabular}

Anaes., anaesthetist; SHO, Senior House Officer; VA, visual acuity; CF, counting fingers; HM, hand movements.

${ }^{a}$ Amblyopic eye. 


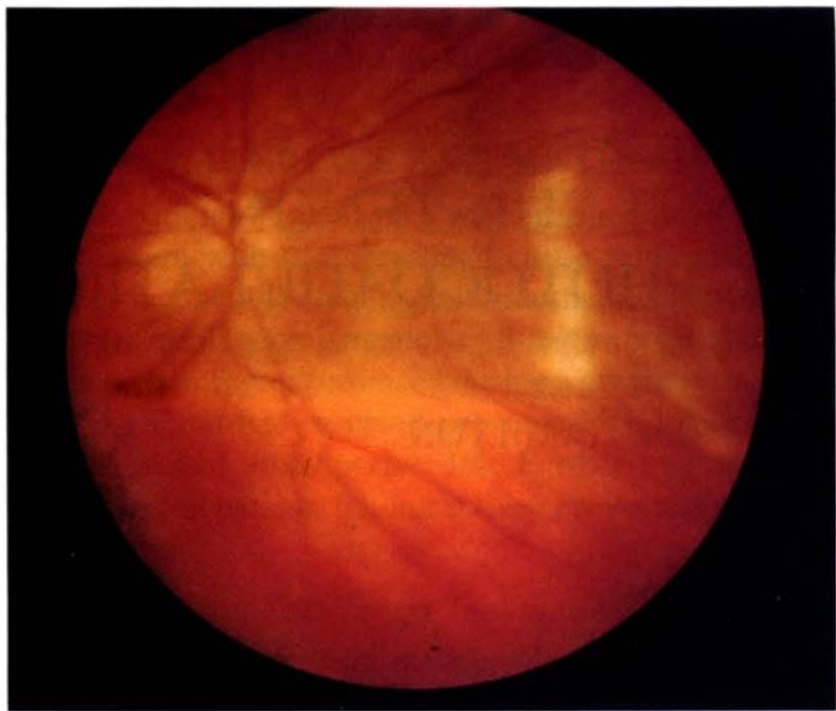

Fig. 1. Superonasal scar following scleral perforation.

retrobulbar technique for cataract surgery. The majority of these cases needed treatment with either laser photocoagulation or retinal detachment surgery with or without vitrectomy. Kimble et $a l^{4}{ }^{4}$ described a case of ocular perforation during peribulbar anaesthesia in 1987 that needed vitrectomy and retinal reattachment. Gizzard and Roseman ${ }^{5}$ mention 5 cases occurring during peribulbar anaesthesia.

At the time of the perforations this unit's policy was switching from general to local anaesthesia, and from retrobulbar to peribulbar anaesthesia, for the majority of surgical procedures. The administration of local anaesthesia was being transferred from experienced ophthalmic surgeons to anaesthetists and junior ophthalmic staff. All 5 cases received peribulbar injections: 3 by a Consultant Anaesthetist and the other 2 by junior ophthalmic SHOs.

The cases we describe differ from most of the previously reported cases in that none required further intervention. In Rinkoff's series ${ }^{3}$ only 1 was noted to have a scleral perforation. Our patients all showed peripheral, white linear scars with no evidence of overlying retinal holes or tears. There was no evidence of intraocular injection of anaesthetic agents as described by Lincoff $\mathrm{et} \mathrm{al}^{6}$

Three of 5 perforations occurred during the second supranasal injection and this has led to a change in peribulbar technique in this department. The majority of peribulbar anaesthetics are now performed using one injection with a technique similar to that described by Whitsett $e t$ $a l .{ }^{7}$ We use a 1 inch 25 gauge needle and inject through the lower lid between the middle and outer thirds. This technique has proved to be effective and since its adoption we have had only 1 perforation in 972 procedures. This patient had an inferotemporal perforation with a dense vitreous haemorrhage. She was referred to a vitreoretinal sur-

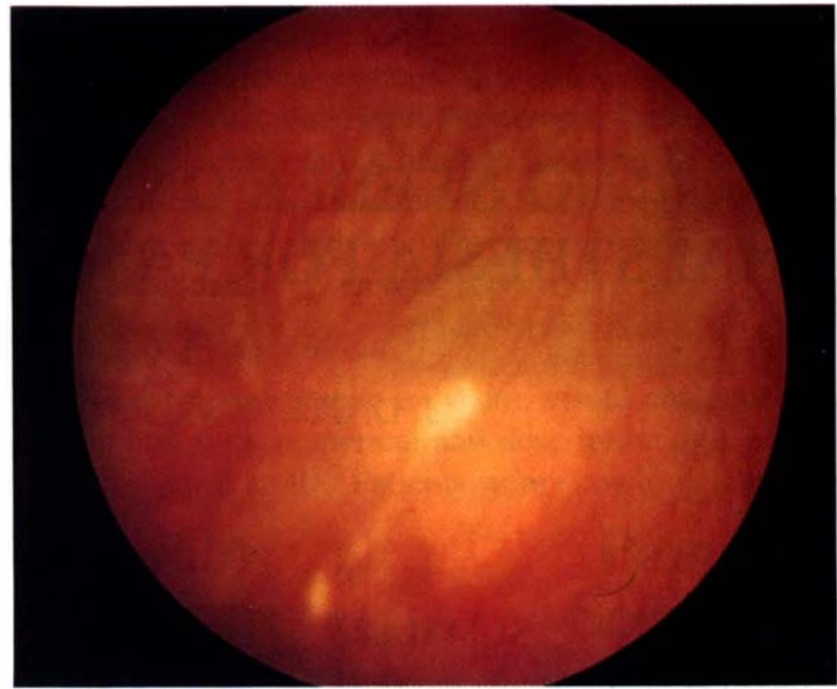

Fig. 2. Inferotemporal scar following scleral perforation.

geon and underwent vitrectomy for an inferior retinal detachment.

Peribulbar anaesthesia has been shown to be safe and effective. ${ }^{8}$ Scleral perforation is an unusual complication and in our experience it need not result in permanent visual impairment. We hope that by recognising the problems in our administration of the anaesthetic and therefore changing our anaesthetic technique we will reduce the risk of further scleral perforation.

Key words: Local anaesthesia, Peribulbar anaesthesia, Scleral perforation.

\section{REFERENCES}

1. Davis DB, Mandel MR. Posterior peribulbar anaesthesia: altemative to retrobulbar anaesthesia. J Cataract Refractive Surg 1986;12:182-4.

2. Ramsey RC, Knoblach WH. Ocular perforation following retrobulbar anaesthesia for retinal detachment surgery. Am J Ophthalmol 1978;86:61-4.

3. Rinkoff JS, Doft BH, Lobes LA. Management of ocular penetration from injection of local anaesthesia preceding cataract surgery. Arch Ophthalmol 1991;109:1421-5.

4. Kimble JA, Morris RE, Witherspoon CE, Feist RM. Globe perforation from peribulbar injection. Arch Ophthalmol 1987; 105:749.

5. Gizzard WS, Roseman R. An epidemic of ocular perforations associated with ocular anaesthesia (abstract). Ophthalmology 1990;97:106.

6. Lincoff $\mathrm{H}$, Zweifach $\mathrm{P}$, Brodie $\mathrm{S}$, et al. Intraocular injection of lidocaine. Ophthalmology 1985;92:1587-91.

7. Whitsett JC, Balyeat HD, McClure MD. Comparison of one injection-site peribulbar anaesthesia and retrobulbar anaesthesia. J Cataract Refractive Surg 1990;16:243-5.

8. Murdoch IE. Peribulbar vs retrobulbar anaesthesia. Eye 1990; 4:445-9. 